\title{
GENERALIZED 'USEFUL' NON-SYMMETRIC DIVERGENCE MEASURES AND INEQUALITIES
}

\author{
ReETu Kumari AND D. K. Sharma
}

\begin{abstract}
In the present paper we consider one parameter generalizations of some 'useful' non symmetric divergence measures. All the generalizations considered can be written as particular cases of Csiszar f-divergence. Under some conditions of probability distributions, inequalities among generalized 'useful' relative divergence measures are obtained.
\end{abstract}

Mathematics subject classification (2010): 94A17, 26D15.

Keywords and phrases: 'Useful' relative information, Csiszar's f-divergence, 'useful' divergence, 'useful' relative information of type s, information inequalities.

\section{REFERENCES}

[1] A. Bhattacharyya, Some Analogues to the Amount of Information and Their uses in Statistical Estimation, Sankhya, 8 (1946), 1-14.

[2] U. S. BhaKaR And D. S. Hooda, Mean value characterization of 'useful' information measures, Tamkang Journal of Mathematics, 24 (1993), 383-39.

[3] J. Burbea, C. R. Rao, Entropy Differential Metric, Distance and Divergence Measures in 3. Probability Spaces: A Unified Approach, J. Multi. Analysis, 12 (1982), 575-596.

[4] I. CSISZ'AR, Information Type Measures of Differences of Probability Distribution and Indirect Observations, Studia Math. Hungarica, 2 (1967), 299-318.

[5] I. Csisz'AR, On Topological Properties of f-Divergences, Studia Math. Hungarica, 2 (1967), 329339.

[6] S. S. Dragomir, Some Inequalities for the Csisz'ar f-Divergence - Inequalities for Csisz'ar f-Divergence in Information Theory - Monograph - Chapter I - Article 1http://rgmia.vu.edu.au/monographs/csiszar.htm.

[7] S. S. DRAGOMIR, Other Inequalities for Csisz'ar Divergence and Applications - Inequalities for Csisz'ar f-Divergence in Information Theory - Monograph - Chapter I - Article 4http://rgmia.vu.edu.au/monographs/csiszar.htm.

[8] S. S. Dragomir, V. Gluscevic and C. E. M. Pearce, Approximations for the Csisz'ar fDivergence via Midpoint Inequalities, in Inequality Theory and Applications - Volume 1, Y. J. Cho, J. K. Kim and S. S. Dragomir (Eds.), Nova Science Publishers, Inc. Huntington, New York, (2001), $139-154$.

[9] S. S. Dragomir, J. Sunde And C. Buse, New Inequalities for Jeffreys Divergence Measure, Tamsui Oxford Journal of Mathematical Sciences, 16(2)(2000), 295-309.

[10] E. Hellinger, Neue Begrundung der Theorie der quadratischen Formen von unendlichen vielen Veranderlichen, J. Reine Aug. Math., 136 (1909), 210-271.

[11] H. Jeffreys, An Invariant Form for the Prior Probability in Estimation Problems, Proc. Roy. Soc. Lon., Ser. A, 186 (1946), 453-461.

[12] S. Kullback And R. A. Leibler, On Information and Sufficiency, Ann. Math. Statist., 22 (1951), 79-86.

[13] P. Kumar and I. J. TAneja, Relative information of type s, Csisz'ar's f-divergence and information inequalities, Information Sciences, 166 (2004), 105-125. 
[14] K. PeARSon, On the Criterion that a given system of deviations from the probable in the case of correlated system of variables is such that it can be reasonable supposed to have arisen from random sampling, Phil. Mag., 50 (1900), 157-172.

[15] A. Sgarro, Informational Divergence and the Dissimilarity of Probability Distributions, Estratto da Calcolo, Vol. XVII, (3) (1981), 293-302.

[16] R. Sibson, Information Radius, Z. Wahrs. Und verw Geb., (14) (1969), 149-160.

[17] I. J. TANejA, On Generalized Information Measures and Their Applications, Chapter in: Advances in Electronics and Electron Physics, Ed. P. W. Hawkes, Academic Press, 76 (1989), 327-413.

[18] I. J. TANeJA, New Developments in Generalized Information Measures, Chapter in: Advances in Imaging and Electron Physics, Ed. P. W. Hawkes, 91 (1995), 37-135.

[19] I. J. TANEJA, Generalized Information Measures and their Applications, on line book: http://www.mtm.ufsc.br/ taneja/book/book.html, (2001).

[20] I. J. TANEJA, Generalized Relative Information and Information Inequalities, Journal of Inequalities in Pure and Applied Mathematics, 5(1) (2004),Art.21, 1-19.

[21] I. J. TANeJa, Bounds on Triangular Discrimination, Harmonic Mean and Symmetric Chi-square Divergences, Journal of Concrete and applicable Mathematics, 4(1) (2006), 91-111.

[22] I. J. TANeJA, Relative Divergence Measures and Information Inequalities - To appear in: Inequality Theory and Applications, Y. J. Cho, J. K. Kim and S. S. Dragomir (Eds.), Nova Science Publishers, Inc. Huntington, New York, 4 (2004).

[23] I. J. TANEJA, On a Difference of Jensen Inequality and its Applications to Mean Divergence Measures, - RGMIA Research Report Collection, http://rgmia.vu.edu.au, 7(4) (2004),Art. 16.

[24] I. J. TANEJA AND P. KUMAR, Relative Information of Type s, Csisz'ar f-Divergence, and Information Inequalities, Information Sciences, 166(1-4)(2004), 105-125. Also in: - RGMIA Research Report Collection, http://rgmia.vu.edu.au, 6(3) (2003),Art. 12. 